\title{
Increased Serum G Protein-coupled Estrogen Receptor 1 Levels and Its Diagnostic Value in Drug Naïve Patients with Major Depressive Disorder
}

\author{
Ebru Findikli ${ }^{1}$, Ergül Belge Kurutas ${ }^{2}$, Mehmet Akif Camkurt ${ }^{3}$, Mehmet Fatih Karaaslan ${ }^{1}$, Filiz Izci ${ }^{4}$, \\ Hüseyin Avni Fındıklı ${ }^{5}$, Selçuk Kardaş ${ }^{1}$, Berat Dag $^{1}$, Hatice Altun ${ }^{6}$ \\ Departments of ${ }^{1}$ Psychiatry, ${ }^{2}$ Biochemistry, and ${ }^{6}$ Child and Adolescent Psychiatry, Faculty of Medicine, Kahramanmaraş Sütçü Imam University, \\ Kahramanmaraş, ${ }^{3}$ Department of Psychiatry, Afşin State Hospital, Kahramanmaraş, ${ }^{4}$ Department of Psychiatry, Bilim University, Istanbul, \\ ${ }^{5}$ Department of Internal Medicine, Adiyaman University, Adıyaman, Turkey
}

\begin{abstract}
Objective: The facts that depression is more prevalent in females than in males and females are exposed to depression more commonly during certain hormonal fluctuating periods indicate the role of sex hormones in physiopathology. Estrogen acts over estrogen receptors alpha and beta and recently identified G protein-coupled estrogen receptor 1 (GPER1). The present study aimed, for the first time, to evaluate serum GPER1 levels in drug-naïve major depressive disorder (MDD) patients.

Methods: The study included 56 newly diagnosed drug-naïve MDD patients aged between 18 and 50 years and 42 age- and gender-matched healthy volunteers. Medical history was obtained and physical examinations, laboratory tests, and the Hamilton Depression Rating Scale (HAM-D), Hamilton Anxiety Rating Scale (HAM-A) were performed. The serum GPER1 levels were measured.

Results: The HAM-D score was significantly higher in the MDD patients than in the controls. The GPER1 level was significantly higher in the MDD patients than in the controls. A positive correlation was found with GPER1 levels and depression scores. The receiver operating characteristic analysis revealed sensitivity, specificity, positive predictive value, and negative predictive value as $82.1 \%, 90.5 \%, 92.0 \%$, and $79.2 \%$, respectively, for the presence of depression, when the serum GPER1 value was $\geq 0.16$. Conclusion: This study demonstrated significantly higher serum GPER1 levels in the MDD patients than in the controls, a positive correlation was found between GPER1 levels and depression scores and serum GPER1 level was valuable in predicting the presence of depression
\end{abstract}

KEY WORDS: Serum G protein-coupled estrogen receptor 1; Major depressive disorder; Estrogens; Diagnostic value.

\section{INTRODUCTION}

Major depressive disorder (MDD) is among the common and important mental health problems. The lifetime prevalence of MDD is estimated to be $1.5-19.0 \%$ (median, $9.4 \%) .{ }^{1)}$ It is known that female sex hormones like estrogen and progesterone affect emotions and cognitions and lead females to differently response to stress as compared with males. ${ }^{2}$ The facts that depression, which is one of the stress-related disorders, is more prevalent in females than in males and females are exposed to depression more commonly during certain hormonal fluctuating periods in-

\footnotetext{
Received: September 7, 2016/ Revised: October 13, 2016

Accepted: October 26, 2016

Address for correspondence: Ebru Findikli, MD

Department of Psychiatry, Faculty of Medicine, Kahramanmaras

Sütçü Imam University, Kahramanmaraş, Turkey

Tel: +90-3442803367, Fax: +90-3442803409

E-mail: ebrukanmaz@gmail.com
}

dicate the importance of sex hormones in physiopathology. ${ }^{3-5)}$ It has been demonstrated that estrogen is involved in cycle-dependent mood disorders, such as premenstrual syndrome or postpartum and menopausal depressive disorders ${ }^{6,7)}$ and that estrogen has a wide range of interactions with neuronal signaling. ${ }^{8)}$

Estrogen exerts its effects through two different classes of receptors, which are the nuclear receptors (estrogen receptor alpha $[E R \alpha]$ and estrogen receptor beta $[E R \beta])$, and the membrane-bound $\mathrm{G}$ protein-coupled receptor(s). ${ }^{9}$ Studies on G protein-coupled receptor, which has been recently discovered and called as GPR30, have demonstrated that this intracellular and transmembrane receptor acts in rapid, non-genomic estrogen signaling. It has later been called as $\mathrm{G}$ protein-coupled estrogen receptor 1 (GPER 1). ${ }^{9)}$ In certain cases, co-expression of ER $\alpha, E R \beta$, and GPER1 suggests an interaction between these receptors. ${ }^{9)}$ In a study, an increase in anxiety symptoms

(C) This is an Open-Access article distributed under the terms of the Creative Commons Attribution Non-Commercial License (http://creativecommons.org/licenses/by-nc/4.0) which permits unrestricted non-commercial use, distribution, and reproduction in any medium, provided the original work is properly cited. 
has been reported in ER $\beta$ knockout mice together with increases in amygdala response and 5-hydroxytryptamine 1A receptor expression, ${ }^{10)}$ suggesting the role of estrogen receptors in the regulation of serotonin and the importance of estrogen in emotional processing. Information on the action mechanism of GPER1 is based on in vitro studies or experimental animal studies; nevertheless, its mechanism of action has not been clarified yet. ${ }^{11,12)}$ Recently, GPER1 has been reported to have a role in estradiol-mediated effects on mood in a mouse model of depression. ${ }^{13)}$ Additionally, in a recent study, GPER1 has been reported to have a potential to mediate the effects of anxiogenic estradiol in both male and female mice. ${ }^{14)}$

The diagnosis of MDD is made with subjective criterias according to Diagnostic and Statistical Manual of Mental Disorders, fourth edition (DSM-IV) or fifth edition (DSMV). The objective markers are yet had not identified for the diagnosis of psychiatric diseases. The diagnostic value of peripheral biomarkers is more important than other biomarkers because their collection and use is easy and suitable in clinical practice. Previously a groving body of research determined inflamation ${ }^{15,16)}$ oxidative parameters $^{17,18)}$ and etc. as biomarkers in MDD and anxiety disorders. Estrogen receptors have been identified in polymorphonuclear and mononuclear leukocytes isolated from peripheral blood and blood vessel endothelium of both men and women. ${ }^{19,20)}$ GPER1 is widely expressed in the human body, both in normal and pathological tissues. It is localized in the cell membrane as well as in intracellular membranes. ${ }^{21,22)}$ Antibodies against various subcellular marker proteins can be used to determine the intracellular localization of GPER1 in native cells. ${ }^{22}$ )

In our previous and first human serum study (with a serum specific kit) we determined significantly higher serum GPER1 levels in generalized anxiety disorder patients than in the controls, a positive correlation between GPER1 levels and anxiety scores and serum GPER1 level was valuable in predicting the presence of generalized anxiety disorder. $^{23)}$

Although estrogen has an important role in mood through GPER1, to the best of our knowledge, there is no study investigating serum GPER1 levels and its diagnostic value in MDD in humans. Therefore, the present study aimed to assess serum GPER1 levels in drug-naïve patients with MDD.

\section{METHODS}

\section{Patients}

The present study included 56 patients aged between 18 and 50 years who were newly diagnosed with MDD according to DSM-IV at their first admission. All patients were drug-naïve. The control group consisted of age- and gender-matched 42 healthy volunteers. All participants were assessed by a trained clinical psychiatrist. The study protocol was approved by the Scientific Research Ethics Committee of Kahramanmaraş Sütçü Imam University and a detailed signed informed consent was obtained from each patient and control subject. The investigation was carried out in accordance with the latest version of the Declaration of Helsinki.

Exclusion criteria were being pregnant or postmenopausal, having irregular menstrual cycle (anovulatory cycle), receiving hormone replacement therapy (e.g., oral contraceptives), having endocrine disorders (diabetes mellitus, impaired levels of thyroid stimulating hormone [TSH]), receiving drugs known to influence prolactin level (e.g., metoclopramide, somatostatin uptake inhibitors, calcium channel blockers, histamine-2 receptor antagonists), being an alcohol and/or substance addict, and having a psychiatric disorder other than MDD or a concomitant physical disease.

Demographic data and medical history of the patients and control subjects were recorded. Their physical examination and required laboratory analyses were performed. The Hamilton Depression Rating Scale (HAM-D) and Hamilton Anxiety Rating Scale (HAM-A) were used in all patients and control subjects.

\section{Laboratory Measurements}

Blood sample of each study subject were collected between 8.00 am and 11.00 am and transferred to the Department of Biochemistry for the analyses. The measurements of fasting blood glucose (FBG), TSH, estradiol and prolactin were performed by standard laboratory methods using an automatic analyzer (Adams HA-8160, ADVIA Centaur XP Immunoassay System; Siemens, Dublin, Ireland). TSH, estradiol and prolactin levels analysed with raddioimmunoassay method. The subjects with normal levels according to sex and age of FBG,TSH and prolactin included the study.

For the analysis of GPER1, fasting venous blood samples $(10 \mathrm{ml})$ from the patients and healthy controls were collected into tubes without anticoagulant. The collected blood samples were centrifuged at 5,000 $g$ for 10 minutes 
at $4^{\circ} \mathrm{C}$. The serum samples were separated from the clotted blood and then stored in acid-washed tubes at $-20^{\circ} \mathrm{C}$ until analyses. The serum levels of GPER 1 were measured by a quantitative sandwich enzyme immunoassay technique (ELISA) using a commercial kit (SEG045Hu; Cloud-Clone Corp., Houston, TX, USA) according to the manufacturer's instruction.

\section{Statistical Analysis}

The Statistical Package for the Social Sciences for Windows (version 16; SPSS Inc., Chicago, IL, USA) was used for data analysis. Descriptive statistics were performed. The patient and control groups were compared by chi-square test for categorical variables. Spearman's correlation analysis was performed to assess the correlation between GPER 1 levels and HAM-D scores. A $p$ value less than 0.05 was considered statistically significant. A receiver operating characteristic (ROC) curve was plotted to obtain a cut-off value of GPER1 for predicting the presence of depression.

\section{RESULTS}

In the present study, 56 patients diagnosed with MDD (MDD group) and 42 healthy controls (control group) were included. There was no difference between the two groups in terms of age and gender (Table 1). HAM-A scores were $<17$ in patient and control groups.

The HAM-D score of the MDD group were significantly higher than that of the control group. The serum GPER1 levels were significantly higher in the MDD group than in the control group (Table 2, Fig. 1). The levels of TSH $(1.20 \pm[1-1.85] ; 1.60 \pm[1-2] \mathrm{mIU} / \mathrm{L})$, estradiol $(99.2 \pm 12.3 ; 149.2 \pm 26.1 \mathrm{pg} / \mathrm{ml})$ and prolactin $(10.11 \pm$ $4.52 ; 11.97 \pm 5.54 \mathrm{ng} / \mathrm{ml}$ ) levels were in normal range in patient and control group respectively ( $p>0.05$ in all). According to Spearman's correlation analysis, there was a positive significant correlation between GPER1 level and

Table 1. Demographic characteristics of the patients with MDD and healthy control subjects

\begin{tabular}{lccc}
\hline Characteristic & $\begin{array}{c}\text { MDD group } \\
(n=56)\end{array}$ & $\begin{array}{c}\text { Control group } \\
(n=42)\end{array}$ & p value \\
\hline Age $(y r)$ & $33.5 \pm 11.23$ & $36.57 \pm 9.86$ & 0.162 \\
Gender & $22(39.3)$ & $18(42.9)$ & 0.722 \\
Male & $34(60.7)$ & $24(57.1)$ & \\
Female & & & \\
\hline
\end{tabular}

Values are presented as mean \pm standard deviation or number (\%). MDD, major depressive disorder

We didn't find any difference between groups in terms of gender and age.
HAM-D score $(\mathrm{r}=0.586, p<0.001)$.

The ROC analysis revealed that GPER1 had a predictive value for the presence of depression (area under the curve [AUC], 0.92; 95\% confidence interval [CI], $0.87-0.98 ; p<0.001)$. When the GPER1 value was $\geq 0.16$, the sensitivity, specificity, positive predictive value, and negative predictive value for the presence of depression were $82.1 \%, 90.5 \%, 92.0 \%$, and $79.2 \%$, respectively (Fig. 2). The GPER1 level was under the cut-off point in all subjects in the control group.

\section{DISCUSSION}

The main outcome of the present study was that the serum GPER1 level was significantly higher in the patients with MDD than in the controls. A positive correlation was

Table 2. Hamilton Depression scores and GPER1 and estradiol levels of patients with MDD and healthy controls

\begin{tabular}{lccr}
\hline & $\begin{array}{c}\text { MDD group } \\
(\mathrm{n}=56)\end{array}$ & $\begin{array}{c}\text { Control group } \\
(\mathrm{n}=42)\end{array}$ & p value \\
\hline HAM-D score & $18 \pm 4.1$ & $7 \pm 3.68$ & $<0.001$ \\
GPER1 $(\mathrm{ng} / \mathrm{ml})$ & $0.28(0.19-0.38)$ & $0.11(0.07-0.13)$ & $<0.001$ \\
$\quad$ Male & $0.30(0.26-0.40)$ & $0.11(0.07-0.13)$ & $<0.001$ \\
Female & $0.27(0.14-0.37)$ & $0.11(0.07-0.14)$ & $<0.001$ \\
Estradiol $(\mathrm{pg} / \mathrm{ml})$ & $99.2(12.3)$ & $149.2(26.1)$ & 0.430 \\
$\quad$ Male & $55.30(2.98)$ & $43.30(7.89)$ & 0.630 \\
$\quad$ Female & $127.5(18.75)$ & $224.15(594.88)$ & 0.850 \\
\hline
\end{tabular}

Values are presented as mean \pm standard deviation, median (interquartile range), or mean (standard error of mean).

GPER 1, serum $G$ protein-coupled estrogen receptor 1; MDD, major depressive disorder; HAM-D, the Hamilton Depression Rating Scale. Ham-D scores and GPER-1 levels were statistically different between groups; $p<0.001$. There was no difference between groups in term of estradiol levels.

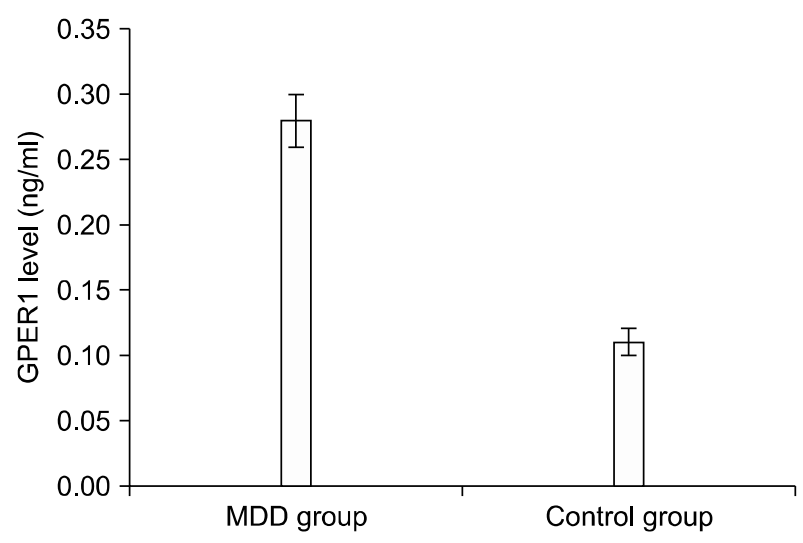

Fig. 1. Serum $G$ protein-coupled estrogen receptor 1 (GPER1) levels of the major depressive disorder (MDD) and control groups. Mean \pm standard error of mean: $0.28 \pm 0.02$ for MDD group; $0.11 \pm$ 0.01 for control group. 


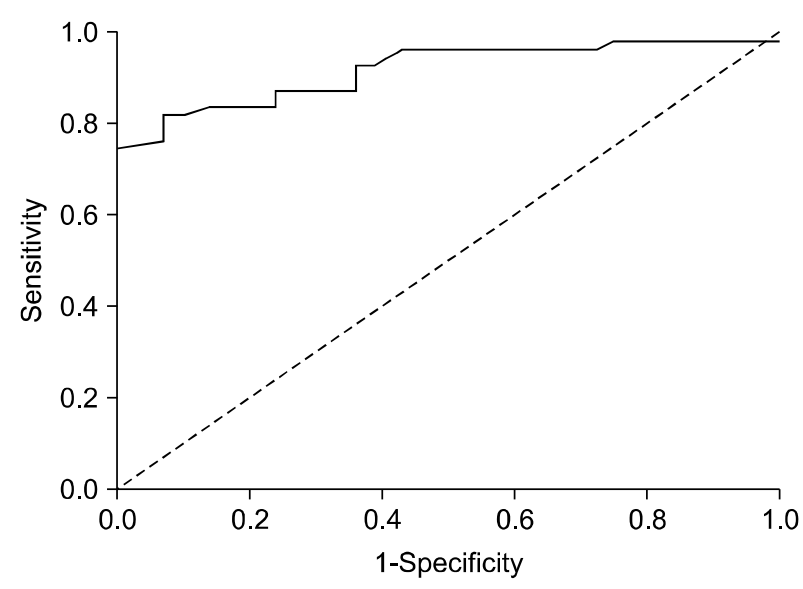

Fig. 2. Receiver operating characteristic (ROC) curve for serum $G$ protein-coupled receptor 1 (GPER1).

Area under curve (AUC) was 0.92 for GPER-1. Cut-off point was detected as $0.16 \mathrm{ng} / \mathrm{ml}$.

This curve combines the information of the true positive rate and the true negative rate, and the AUC is a measure of the overall discriminative power of GPER1.

found between GPER1 serum levels and depression scores. Furthermore, we found a good diagnostic value for increased GPER1 activity.

Estrogen is known to have favorable effects on neurological system such as increasing neuronal connectivity and improving cognitive performance. ${ }^{24)}$ The amygdala, the hippocampus, and some non-mesial temporal structures have a central role in mood regulation and these structures are continuously sensitive to fluctuations in the sex hormone levels like estrogen. ${ }^{25)}$ Estrogen has facilitating effect on various neurotransmitter systems, which regulates mood and affect, and data on this issue are gradually increasing. ${ }^{26,27)}$ The serotoninergic system is particularly related to mood. ${ }^{28-32)}$ The factors increasing the serotonergic and noradrenergic transmission have also been suggested to have efficacy in the treatment of depression in the peri- and post-menopausal periods. ${ }^{33-35)}$

It has been reported that favorable effect of estrogen on mood is associated with ER $\beta$ signaling and that estrogen leads to a decrease in glucocorticoid activity via ER $\beta$ and has antidepressant activity. ${ }^{4}$ In an investigation it was suggested that women with the AA alleles of ER $\beta$ RS4986938 had the higher prevalence of lifetime major depression than women with other allele frequencies and carriers of the AA alleles in $\mathrm{ER} \alpha$ polymorphism RS9340799 had increased prevalence of lifetime major depression only among lifetime post-menopausal hormone users. ${ }^{36)}$ Administration of estrogen receptor antagonists to the hippocampus enhances depression. Knowing the mechanism by which estradiol influences depression is important in order to improve its therapeutic potential. $^{37)}$

There are evidences that GPER 1 might have a role in mood disorders. ${ }^{24,38)}$ In the mouse, for instance, the localization of GPER1 has been reported in a number of nuclei, including the paraventricular nucleus, hypothalamic nucleus, septal complex nuclei, hippocampal nuclei, and supraoptic nucleus that play a role in emotional control. ${ }^{39)}$

Increasing knowledge about GPER1 and having information on the expression levels of GPER 1 in various diseases may contribute to the diagnostic and prognostic approaches and enable to use GPER1 agonist or antagonists in individualized treatment approaches. ${ }^{40)}$ Appropriate doses of estrogen in the treatment of depression in females during hormonal fluctuating periods suppress cyclic hormonal changes and the mood-enhancing effect of estrogen improves depression. ${ }^{41)}$ Experimental studies on animals have suggested that antidepressant-like effect of estradiol is mediated by ER $\beta$ and GPER 1 and that GPER 1 might be a new target in the treatment of depression. ${ }^{42,43)}$

At present, diagnosis of MDD is based on the verbal declaration of symtoms, clinical behavioral observations, and mental status examinations that increases the probability of misdiagnosis. There is a serious need to find a practical biomarker for the proper diagnosis of MDD. Previous studies found that some biochemical markers have diagnostic value for MDD. Karlović et al. ${ }^{44)}$ found a significant diagnostic value of serum brain-derived neurotrophic factor in diagnosing MDD with ROC analysis. They found the AUC was 0.892 with a $95 \%$ confidence level. In another study, Fan et al. ${ }^{45)}$ found miRNAs were up-regulated in peripheral blood mononuclear cells of patients with MDD and by ROC curve analysis, AUC of these miRNAs was 0.636 . They concluded that altered expression of miRNAs in peripheral blood mononuclear cells might be able to serve as specific biomarker for diagnosis of MDD. ${ }^{45)}$ Furthermore, Camkurt et al. ${ }^{46)}$ denoted AUC value of 1.0 for malondialdehyde in major depression. Our study illustrates possible implication for estrogen rereceptor activity as an valuable research area for detection of peripheral biomarkers.

There are limited studies about GPER levels in human with psychiatric diseases. Only in our previous study we determined significantly higher serum GPER1 levels in generalized anxiety disorder patients than controls. Similiarly our present study, in ROC analysis it was found that the diagnostic value of GPER1 levels for generalized anxiety disorder was significantly high. ${ }^{23)}$ It seems anxi- 
ety and depression is separately related with higher GPER1 levels. It is a question yet whether GPER1 levels are specific for MDD. So further studies are needed to clarify this question.

Depression is more prevalent in females than in males. Female sex hormones estrogen has an important role in mood through GPER1. According to our hypotesis it is expected to be that GPER1 is more selective biomarker for depression in female rather than that in men. But, both male and female MDD group had higher GPER1 levels than that of each control group. In rat studies there is controversial effect of GPER1 according to sex on mood. Some studies show equal effect in both gender ${ }^{14,47,48)}$ and the others show gender differences. ${ }^{49)}$ In our previous study in subgroup analysis, GPER1 levels were significantly increased in patients with anxiety disorder, regardless of gender. ${ }^{20)}$ So it seems that GPER1 levels show an increase related MDD, independent from sex.

The major limitations of the present study were the small number of patients, its cross-sectional design, and the lack of pre- and post-treatment receptor level measurement. The other limitation was that our patient group was fertile men and women. But depression also affects non-fertile males and women. Further studies might include these groups to clarify the effect of GPER1.

Nevertheless, to our knowledge, there is no study in the literature assessing the serum GPER1 levels in MDD patients; accordingly, this study has the feature of being the first study on this issue. The outcome of the present study is important in terms of providing data for a treatment approach through target receptors in MDD, considering this approach particularly in refractory cases, and understanding the relationship of estrogen with depressive or antidepressant effects. Understanding the mechanisms that regulate the relations between estrogen and depression would contribute to the development of therapeutic strategies.

The present study demonstrated that the serum GPER1 levels were significantly higher in the patients with MDD than in the control subjects and have a positive correlation with depression scores. Moreover, it was observed that GPER1 level had a good diagnostic value for the presence of depression. Further studies are needed to clarify the possible biomarker value of GPER1, in this baseline our study should be considered as a preliminary study.

\section{Acknowledgments}

This study is supported by Scientific Research Project Unit of Kahramanmaras Sütçü Imam University (Project
No: 2014/3-46 M).

\section{REFERENCES}

1. Kessler RC. The costs of depression. Psychiatr Clin North Am 2012;35:1-14.

2. ter Horst JP, de Kloet ER, Schächinger H, Oitzl MS. Relevance of stress and female sex hormones for emotion and cognition. Cell Mol Neurobiol 2012;32:725-735.

3. Soares CN. Depression in peri- and postmenopausal women: prevalence, pathophysiology and pharmacological management. Drugs Aging 2013;30:677-685.

4. Solomon MB, Herman JP. Sex differences in psychopathology: of gonads, adrenals and mental illness. Physiol Behav 2009;97:250-258.

5. Studd J, Nappi RE. Reproductive depression. Gynecol Endocrinol 2012;28 Suppl 1:42-45.

6. Payne JL. The role of estrogen in mood disorders in women. Int Rev Psychiatry 2003;15:280-290.

7. Westberg L, Eriksson E. Sex steroid-related candidate genes in psychiatric disorders. J Psychiatry Neurosci 2008;33: 319-330.

8. Wittmann W, Schunk E, Rosskothen I, Gaburro S, Singewald N, Herzog H, et al. Prodynorphin-derived peptides are critical modulators of anxiety and regulate neurochemistry and corticosterone. Neuropsychopharmacology 2009;34: 775-785.

9. Barton M. Position paper: The membrane estrogen receptor GPER--Clues and questions. Steroids. 2012;77:935-942.

10. Krezel W, Dupont S, Krust A, Chambon P, Chapman PF. Increased anxiety and synaptic plasticity in estrogen receptor beta -deficient mice. Proc Natl Acad Sci U S A 2001;98:12278-12282.

11. Kim MJ, Kim TH, Lee HH. G-protein coupled estrogen receptor (GPER/GPR30) and women's health. J Menopausal Med 2015;21:79-81.

12. Langer G, Bader B, Meoli L, Isensee J, Delbeck M, Noppinger PR, et al. A critical review of fundamental controversies in the field of GPR30 research. Steroids 2010;75:603-610.

13. Dennis MK, Burai R, Ramesh C, Petrie WK, Alcon SN, Nayak TK, et al. In vivo effects of a GPR30 antagonist. Nat Chem Biol 2009;5:421-427.

14. Kastenberger I, Lutsch C, Schwarzer C. Activation of the G-protein-coupled receptor GPR30 induces anxiogenic effects in mice, similar to oestradiol. Psychopharmacology (Berl) 2012;221:527-535.

15. Hiles SA, Baker AL, de Malmanche T, Attia J. A meta-analysis of differences in IL-6 and IL-10 between people with and without depression: exploring the causes of heterogeneity. Brain Behav Immun 2012;26:1180-1188.

16. Howren MB, Lamkin DM, Suls J. Associations of depression with C-reactive protein, $I L-1$, and $I L-6$ : a meta-analysis. Psychosom Med 2009;71:171-186.

17. Ozcan ME, Gulec M, Ozerol E, Polat R, Akyol O. Antioxidant enzyme activities and oxidative stress in affective disorders. Int Clin Psychopharmacol 2004;19: 89-95.

18. Findikli E, Camkurt MA, Karaaslan MF, Kurutaş EB, Findikli HA, İzci F, et al. The biomarker potential of malondialdehyde, superoxide dismutase and catalase activity in drug naïve, first episode, non-smoker generalized anxiety disorder patients. Clin Psychopharmacol Neurosci 2016. http://www.cpn.or.kr/journal/view.html?uid=496\&vmd $=$ Full \&. [Epub ahead of print] 
19. Han G, Li F, Yu X, White RE. GPER: a novel target for non-genomic estrogen action in the cardiovascular system. Pharmacol Res 2013;71:53-60.

20. Stygar D, Westlund P, Eriksson H, Sahlin L. Identification of wild type and variants of oestrogen receptors in polymorphonuclear and mononuclear leucocytes. Clin Endocrinol (Oxf) 2006;64:74-81.

21. Revankar CM, Cimino DF, Sklar LA, Arterburn JB, Prossnitz ER. A transmembrane intracellular estrogen receptor mediates rapid cell signaling. Science 2005;307: 1625-1630.

22. Sandén C, Broselid S, Cornmark L, Andersson K, Daszkiewicz-Nilsson J, Mårtensson UE, et al. G proteincoupled estrogen receptor $1 / G$ protein-coupled receptor 30 localizes in the plasma membrane and traffics intracellularly on cytokeratin intermediate filaments. Mol Pharmacol 2011;79:400-410.

23. Findiklı E, Camkurt MA, Karaaslan MF, Kurutas EB, Altun $\mathrm{H}$, İzci $\mathrm{F}$, et al. Serum levels of $G$ protein-coupled estrogen receptor 1 (GPER1) in drug-naive patients with generalized anxiety disorder. Psychiatry Res 2016;244:312-316.

24. Prossnitz ER, Barton M. The G-protein-coupled estrogen receptor GPER in health and disease. Nat Rev Endocrinol 2011;7:715-726.

25. Phan KL, Wager T, Taylor SF, Liberzon I. Functional neuroanatomy of emotion: a meta-analysis of emotion activation studies in PET and fMRI. Neuroimage 2002;16: 331-348.

26. van Amelsvoort T, Compton J, Murphy D. In vivo assessment of the effects of estrogen on human brain. Trends Endocrinol Metab 2001;12:273-276.

27. Yaffe K. Estrogens, selective estrogen receptor modulators, and dementia: what is the evidence? Ann N Y Acad Sci 2001;949:215-222.

28. Cyr M, Landry M, Di Paolo T. Modulation by estrogenreceptor directed drugs of 5-hydroxytryptamine- $2 A$ receptors in rat brain. Neuropsychopharmacology 2000;23: 69-78.

29. Matsuda Y, Hirano H, Watanabe Y. Effects of estrogen on acetylcholine release in frontal cortex of female rats: involvement of serotonergic neuronal systems. Brain Res 2002;937:58-65.

30. Mössner R, Daniel S, Albert D, Heils A, Okladnova O, Schmitt A, et al. Serotonin transporter function is modulated by brain-derived neurotrophic factor (BDNF) but not nerve growth factor (NGF). Neurochem Int 2000;36: 197-202.

31. Mössner R, Schmitt A, Syagailo Y, Gerlach M, Riederer P, Lesch KP. The serotonin transporter in Alzheimer's and Parkinson's disease. J Neural Transm Suppl 2000;(60): 345-350.

32. Osterlund MK, Halldin C, Hurd YL. Effects of chronic 17beta-estradiol treatment on the serotonin 5-HT(1A) receptor $m R N A$ and binding levels in the rat brain. Synapse 2000; 35:39-44

33. Joffe H, Soares CN, Petrillo LF, Viguera AC, Somley BL, Koch JK, et al. Treatment of depression and menopauserelated symptoms with the serotonin-norepinephrine reuptake inhibitor duloxetine. J Clin Psychiatry 2007;68: 943-950.

34. Soares CN, Poitras JR, Prouty J, Alexander AB, Shifren JL, Cohen LS. Efficacy of citalopram as a monotherapy or as an adjunctive treatment to estrogen therapy for perime- nopausal and postmenopausal women with depression and vasomotor symptoms. J Clin Psychiatry 2003;64:473-479.

35. Thase ME, Entsuah R, Cantillon M, Kornstein SG. Relative antidepressant efficacy of venlafaxine and SSRIs: sex-age interactions. J Womens Health (Larchmt) 2005;14:609-616.

36. Keyes K, Agnew-Blais J, Roberts AL, Hamilton A, De Vivo I, Ranu $\mathrm{H}$, et al. The role of allelic variation in estrogen receptor genes and major depression in the Nurses Health Study. Soc Psychiatry Psychiatr Epidemiol 2015;50:18931904.

37. Walf AA, Frye CA. A review and update of mechanisms of estrogen in the hippocampus and amygdala for anxiety and depression behavior. Neuropsychopharmacology 2006;31: 1097-1111.

38. Prossnitz ER, Barton M. Signaling, physiological functions and clinical relevance of the $G$ protein-coupled estrogen receptor GPER. Prostaglandins Other Lipid Mediat 2009;89:89-97.

39. Hazell GG, Yao ST, Roper JA, Prossnitz ER, O'Carroll AM, Lolait SJ. Localisation of GPR30, a novel G protein-coupled oestrogen receptor, suggests multiple functions in rodent brain and peripheral tissues. J Endocrinol 2009;202:223236.

40. Prossnitz ER, Barton M. Estrogen biology: new insights into GPER function and clinical opportunities. Mol Cell Endocrinol 2014;389:71-83.

41. Studd JW. A guide to the treatment of depression in women by estrogens. Climacteric 2011;14:637-642.

42. Benmansour S, Weaver RS, Barton AK, Adeniji OS, Frazer A. Comparison of the effects of estradiol and progesterone on serotonergic function. Biol Psychiatry 2012;71:633-641.

43. McAllister CE, Mi Z, Mure M, Li Q, Muma NA. GPER1 stimulation alters posttranslational modification of RGSz1 and induces desensitization of 5-HT1A receptor signaling in the rat hypothalamus. Neuroendocrinology 2014;100:228239.

44. Karlović D, Serretti A, Jevtović S, Vrkić N, Serić V, Peleš AM. Diagnostic accuracy of serum brain derived neurotrophic factor concentration in antidepressant naïve patients with first major depression episode. $J$ Psychiatr Res 2013;47:162-167.

45. Fan HM, Sun XY, Guo W, Zhong AF, Niu W, Zhao L, et al. Differential expression of microRNA in peripheral blood mononuclear cells as specific biomarker for major depressive disorder patients. J Psychiatr Res 2014;59:45-52.

46. Camkurt MA, Fındıklı E, İzci F, Kurutaş EB, Tuman TC. Evaluation of malondialdehyde, superoxide dismutase and catalase activity and their diagnostic value in drug naïve, first episode, non-smoker major depression patients and healthy controls. Psychiatry Res 2016;238:81-85.

47. Anchan D, Clark S, Pollard K, Vasudevan N. GPR30 activation decreases anxiety in the open field test but not in the elevated plus maze test in female mice. Brain Behav 2014:4:51-59.

48. Hart D, Nilges M, Pollard K, Lynn T, Patsos O, Shiel C, et al. Activation of the G-protein coupled receptor 30 (GPR30) has different effects on anxiety in male and female mice. Steroids 2014;81:49-56.

49. Kastenberger I, Schwarzer C. GPER1 (GPR30) knockout mice display reduced anxiety and altered stress response in a sex and paradigm dependent manner. Horm Behav 2014;66:628-636. 